\title{
El quiebre de las ciencias sociales en Chile. Testimonios y repercusiones del 11 de septiembre de 1973 en documentos de la Fundación Ford ${ }^{+}$
}

\author{
The breakdown of the social sciences in Chile. Testimonies and repercussions \\ of September 11, 1973 in documents of the Ford Foundation
}

\author{
Juan Jesús Morales Martín* - Camilo Garber Fuentes**
}

\begin{abstract}
Resumen: Este artículo examina, a partir de los documentos de los agentes de la Fundación Ford, las consecuencias y repercusiones inmediatas que tuvo el Golpe de Estado del 11 de septiembre de 1973 en las ciencias sociales chilenas. Con ello, se observará la puesta en marcha de la estrategia de desarticulación de estas disciplinas acometida por la dictadura cívil-militar; se escucharán testimonios de funcionarios de la Fundación Ford y profesores universitarios respecto a este hecho; y se presenciará la forja de un nuevo escenario histórico que apuntaló el despegue del pensamiento neoliberal.
\end{abstract}

Palabras clave: Ciencias sociales, Chile, Golpe de Estado, Fundación Ford, pensamiento neoliberal.

\begin{abstract}
This article examines, from the documents of the agents of the Ford Foundation, the immediate consequences and repercussions that the Coup d'Etat of 11 September 1973 had on the social sciences in Chile. With this, it will be observed the implementation of the strategy of disarticulation of these disciplines undertaken by the civic-military dictatorship; different voices from officials of the Ford Foundation and university professors will be heard on this fact; and witness the forging of a new historical scenario that shore up the take-off neoliberal thinking.
\end{abstract}

\footnotetext{
+ Este texto se enmarca en el proyecto FONDECYT de Iniciación a la Investigación 2015 N 11150026: "Una alianza para la democracia: la Fundación Ford y el circuito latinoamericano de centros académicos independientes en tiempos de autoritarismo (1969-1990). Un análisis de los casos de CEDES, CEBRAP y CIEPLAN". Además, para esta investigación Juan Jesús Morales Martín fue galardonado con una beca del Archivo de la Fundación Rockefeller (RAC Grants Awards 2015) para realizar una estancia en Nueva York y consultar así archivos, documentos y fondos de la Fundación Ford.

* Español, primer autor, Doctor en Sociología por la Universidad Complutense de Madrid (2012), Académico de planta en la Escuela de Sociología de la Universidad Católica Silva Henríquez, Proyecto FONDECYT de Iniciación a la Investigación $2015 \mathrm{~N}^{\circ} 11150026$, jmoralesma@ucsh.cl

** Chileno, segundo autor, Estudiante de Ciencia Política de la Universidad Diego Portales, Minor en Ciencias Sociales por la misma Universidad (2015). Asistente de investigación del Proyecto FONDECYT de Iniciación a la Investigación 2015 N 11150026, camilo.garber@mail.udp.cl
} 
Keywords: Social Sciences, Chile, Coup d'Etat, Ford Foundation, Neoliberal Thinking.

Recibido: 10 septiembre 2017

Aceptado: 23 noviembre 2017

\section{Introducción. Las ciencias sociales en Chile antes del 11 de septiembre}

Poco a poco las ciencias sociales en Chile vuelven a tomarse a sí mismas como objeto de revisión historiográfica. ${ }^{1}$ Estos esfuerzos constituyen de por sí un claro ejemplo de su autorreflexividad y de su capacidad de pensarse críticamente. Esa mirada retrospectiva es la que también ayuda, entre otras cosas, a establecer a sus autores clásicos, a señalar sus instituciones más representativas y a identificar los aportes más originales de su pensamiento. ${ }^{2}$ Por supuesto, este ejercicio posibilita entonces comprender cuál ha sido el proceso en que se han configurado estas disciplinas como, sobre todo, advierte sobre la forma en cómo las ciencias sociales, por lo menos en este país, han estado ligadas a los sucesos históricos y se han involucrado en los proyectos políticos desarrollistas, modernizadores y reformistas. ${ }^{3}$ Estos trabajos, como claros ejemplos de esa cualidad de autoobservación, conforman precisamente el marco teórico de referencia de este artículo,

\footnotetext{
${ }^{1}$ Recordemos aquí la capacidad de auto-observación que han manifestado históricamente las ciencias sociales en Chile antes y después del Golpe de Estado de 1973, con trabajos clásicos como los de Hernán Godoy (Orientación y organización de los estudios sociológicos en Chile, Santiago de Chile, Ediciones Universidad de Chile, 1960), María Teresa Lladser (Centros privados de investigación en ciencias sociales en Chile, Santiago de Chile, Academia de Humanismo Cristiano, FLACSO, 1986), o José Joaquín Brunner (El caso de la sociología en Chile: formación de una disciplina, Santiago de Chile, FLACSO, 1988). Entre los últimos esfuerzos y desde diferentes perspectivas destacan, por ejemplo, el libro de Manuel Antonio Garretón, Las ciencias sociales en la trama de Chile y América Latina, Santiago de Chile, LOM, 2014; y diversos textos de Claudio Ramos, tales como "Local and Global Communications in Chilean Social Science: Inequality and Relative Autonomy”, Current Sociology, Vol. 62, No5, 2014, 704-722; El ensamblaje de ciencia social y sociedad. Conocimiento científico, gobierno de las conductas y producción de lo social, Santiago de Chile, Ediciones Universidad Alberto Hurtado, 2012; y (con Andrea Canales y Stefano Palestini) "El campo de las ciencias sociales en Chile: ¿Convergencia disciplinar en la construcción del objeto de estudio?”, Cinta de Moebio, No 33, 2009, 171-194.

${ }^{2}$ Una buena muestra de estas acciones lo prueban trabajos recientes como los de Juan Jesús Morales (José Medina Echavarría. Vida y sociología, México D.F., El Colegio de México, 2017); Carlos Fabián Pressacco y Pablo Salvat ("Norbert Lechner: política y utopía en América Latina", Polis, No 47, 2017); Cristina Moyano ("ONG y conocimiento sociopolítico durante la Dictadura: la disputa por el tiempo histórico de la transición. El caso de los Talleres de Análisis de Coyuntura en ECO, 1987-1992”, Revista Izquierdas, № 27, 2016 , 131); Mónica Iglesias Vázquez ("Saber y poder en la transición chilena: los pobladores como campo de disputa política", Revista de Historia, Vol. 2, № 23, 2016, 65-94); Juan Cristóbal Cárdenas ("Una historia sepultada: el Centro de Estudios Socioeconómicos de la Universidad de Chile, 1965-1973 (a 50 años de su fundación)", De Raíz Diversa, Vol. 2, No 3, 2015, 121-140); y Alexis Cortés ("Modernización, dependencia y marginalidad: itinerario conceptual de la sociología latinoamericana", Sociologias, V. 14, 2012, 214-238).

${ }^{3}$ Carlos Ruiz, De nuevo la sociedad, Santiago de Chile, LOM, 2015.
} 
inserto pues en este diálogo actual y fructífero sobre la historia de las ciencias sociales nacionales.

Pero, además, y tratando de aportar una perspectiva novedosa y original a este campo de conocimiento, este trabajo tributa al debate teórico y empírico reciente por examinar el rol de las fundaciones filantrópicas estadounidenses en los ámbitos académico, científico y cultural de América Latina durante las décadas de 1960 y 1970. ${ }^{4}$ Aquí, en particular, el interés está puesto en cómo la Fundación Ford, con larga presencia en Chile, exploró internamente las repercusiones que tuvo el Golpe de 1973 para las ciencias sociales nacionales. Las valoraciones y representaciones que hizo esa institución sobre ese suceso histórico y sobre esas disciplinas han sido poco estudiadas. Precisamente el acceso a los documentos originales de la Fundación Ford son los que permiten conocer detalles sobre el estado de las ciencias sociales de ese entonces como, a la vez, el examen de ese episodio devela incluso la emergencia del pensamiento económico neoliberal, el cual se consagrará hegemónicamente bajo la dictadura civil-militar. ${ }^{5}$ Por tales motivos, se seguirá una metodología cualitativa basada en el análisis de documentos que permitirá ofrecer nuevos elementos al debate sobre las repercusiones del quiebre democrático chileno.

La selección analítica y el recorte temporal propuesto se justifican porque las ciencias sociales en el Chile de 1973 estaban plenamente institucionalizadas y consolidadas como disciplinas científicas y universitarias. ${ }^{6}$ Gozaban, además, de autonomía académica y eran cosmopolitas y reconocidas internacionalmente. De hecho, Santiago era el centro en América Latina de toda una circulación de científicos extranjeros y latinoamericanos, de

\footnotetext{
${ }^{4}$ Respecto a la bibliografía utilizada como soporte teórico de este debate sobre el papel de las fundaciones filantrópicas estadounidenses en América Latina, destacamos los siguientes trabajos: Silvia E. Braslavsky, "The Ford Foundation and the Relocation of Argentinian Scholars, 1966-1968", Research Reports, Rockefeller Archive Center, Nueva York, 2017; Álvaro Morcillo, "La dominación filantrópica. La Rockefeller Foundation y las ciencias sociales en español (1938-1973)", en Álvaro Morcillo y Eduardo Weisz (eds.), Max Weber en Iberoamérica. Nuevas interpretaciones, estudios empíricos y recepción, México D.F., Fondo de Cultura Económica, CIDE, 2016, 573-605; Fernando Quesada, La Universidad desconocida. El convenio Universidad de Chile-Universidad de California y la Fundación Ford, Mendoza, Universidad Nacional de Cuyo, 2015; Benedetta Calandra, "Del "terremoto" cubano al golpe chileno: políticas culturales de la Fundación Ford en América Latina (1959-1973)", en Benedetta Calandra y Marina Franco (eds.), La guerra fría cultural en América Latina. Desafíos y límites para una nueva mirada de las relaciones interamericanas, Buenos Aires, Editorial Biblos, 2012, 133-149; Benedetta Calandra, "La Ford Foundation y la Guerra Fría Cultural", Americanía, № 1, 2011, 8-25; Diego Pereyra, "American organizations and the development of sociology and social research in Argentina. The case of the SSRC and the Rockefeller Foundation (1927-19669)", Research Reports, Rockefeller Archive Center, Nueva York, 2006.

${ }^{5}$ Para el acopio de fuentes documentales, Juan Jesús Morales Martín fue galardonado con una beca del Archivo de la Fundación Rockefeller (RAC Grants Awards 2015) para realizar una estancia en Nueva York y consultar archivos, documentos y material bibliográfico de la Fundación Ford.

${ }^{6}$ Debemos matizar aquí que este artículo no pretende ser un trabajo descriptivo sobre la historia de la institucionalización de las ciencias sociales en Chile, aunque, obviamente, tendremos en cuenta y problematizaremos algunas de sus etapas. Sin embargo, como texto de referencia recomendamos el clásico escrito de Hernán Godoy sobre el desarrollo de la sociología y de las ciencias sociales chilenas correspondiente al período que va desde 1950 hasta 1973: "El desarrollo de la sociología en Chile. Resumen crítico e interpretativo de su desenvolvimiento entre 1950 y 1973”, Estudios Sociales, No 12, pp. 33-56.
} 
ideas y de nuevas tendencias y teorías sociales que se expandieron por toda la región ${ }^{7} 8$. Recordemos, en este sentido, la larga presencia en Chile de este tipo de instituciones, como la CEPAL, la FLACSO, el ILPES o el PNUD, que desde los años cincuenta venían ejerciendo un muy importante rol en la formación de científicos sociales, en el suministro de especialistas en planificación económica, en industrialización, en asesoría política o en urbanización para toda la región, además de la producción de conocimientos y saberes especializados.

Pero, a su vez, en este proceso de modernización y profesionalización de las ciencias sociales -ligadas a las propias y particulares demandas de desarrollo económico, político y social del país-, participaron otros actores, como las fundaciones privadas extranjeras. De forma específica, la Fundación Ford desempeñó un papel fundamental apoyando con sus donaciones a instituciones públicas y universitarias chilenas. Esta entidad filantrópica estadounidense ayudó también a consolidar y animar el circuito nacional y regional de intercambio y de circulación de conocimientos, como a la vez colaboró en el establecimiento de lazos académicos y de redes intelectuales con profesores y científicos sociales chilenos, latinoamericanos y extranjeros. ${ }^{9}$

Teniendo la Fundación Ford una dilatada presencia en Chile y manteniendo sus agentes contactos y lazos con las ciencias sociales nacionales, además de ser buenos conocedores de la realidad académica, intelectual y política del país, se hace indispensable el estudio desde una perspectiva histórica a la atención prestada por esta institución filantrópica a la complejidad de situaciones, contextos e interacciones vividos a partir del 11 de septiembre de 1973. Por tal motivo, el objetivo principal de este artículo, y de las páginas que siguen, es examinar a partir de los documentos de los agentes y funcionarios de la Fundación Ford las consecuencias y repercusiones inmediatas del Golpe de Estado en las ciencias sociales en un contexto de alta politización. De esta forma, se observará la puesta en marcha de la estrategia de desarticulación de las ciencias sociales chilenas acometida por la dictadura civil-militar; se recogerán distintos testimonios respecto a este hecho y desde distintas posiciones - siempre con el espejo presente de los agentes extranjeros de la Fundación Ford-; y se empezará a intuir el surgimiento de un nuevo escenario histórico y económico nacional que apuntaló el despegue del pensamiento neoliberal y que transformó para siempre la realidad cultural, económica, social y política de este país.

\footnotetext{
${ }^{7}$ Fernanda Beigel, "La FLACSO chilena y la regionalización de las ciencias sociales en América Latina (1957-1973)", Revista Mexicana de Sociología, № 2, México D.F., 2009, 319-349.

${ }^{8}$ Juan Jesús Morales, “José Medina Echavarría y la sociología en Chile. El intento de constituir una "tradición sociológica" en la Escuela Latinoamericana de Sociología”, Revista Central de Sociología, N7, Santiago de Chile, 2012, 79-115.

9 Juan Jesús Morales, "Científicos sociales latinoamericanos en Estados Unidos: cooperación académica, movilidad internacional y trayectorias interamericanas alrededor de la Fundación Ford", DADOS - Revista de Ciencias Sociais, Vol. 60, № 2, 2017, 473-504.
} 


\section{Antecedentes de la Fundación Ford y de su Programa para Latinoamérica.}

Resulta conveniente comenzar este apartado señalando brevemente los orígenes y la naturaleza de la Fundación Ford. Esta institución filantrópica estadounidense, ubicada actualmente en Nueva York, fue creada en el año 1936 como una organización independiente, privada, no lucrativa y no gubernamental, dedicada a financiar programas de cooperación internacional que promuevan el desarrollo, la democracia y la reducción de la pobreza 10 11. En específico, el Programa para Latinoamérica comenzó en 1959, en respuesta al calor de la Revolución socialista en Cuba y con la Guerra Fría como telón de fondo. Las donaciones ejecutadas por el Programa se adicionaron a la asistencia económica, técnica y científica que Estados Unidos dispensó para la región con la Alianza para el Progreso impulsada en 1961 por el presidente John F. Kennedy. ${ }^{12}$

El apoyo financiero de la Fundación Ford resultó entonces fundamental para la modernización de la educación superior de la región, para el establecimiento de programas de becas y de cooperación académica internacional, sobre todo con Estados Unidos, y para que se impulsaran múltiples investigaciones y estudios sobre aspectos sociales, económicos y políticos del desarrollo latinoamericano. A la vez que esta institución filantrópica concedía recursos económicos, se ocupaba también de supervisar en terreno los proyectos financiados y de articular sus relaciones personales y profesionales con los profesores y con las instituciones académicas regionales. En ese sentido, la Fundación Ford estableció en 1962 oficinas en Buenos Aires y en Bogotá. Al año siguiente abriría una oficina en Santiago de Chile, la cual a partir de 1966 operó como sede regional de la institución. Luego en 1965 se abriría otra oficina en Lima ${ }^{13}$. A partir de estas oficinas y a través de sus agentes el principal objetivo, como decimos, era evaluar el destino de las donaciones en la actividad científica y de investigación como el establecimiento de redes y de relaciones de cooperación académica internacional.

Podemos argumentar que estas prácticas establecieron una dinámica de "diplomacia académica" y que los agentes de la Fundación Ford actuaron, en consecuencia, como "diplomáticos académicos", siendo muy relevante su presencia en el caso chileno a la hora de fomentar una red de intercambios institucionales y de circulación de conocimientos y de

\footnotetext{
10 Robert Arnove; Nadine Pinede, "Revisiting the "Big Three” Foundations", Critical Sociology, N 33, Detroit, 2007, 389-435.

${ }^{11}$ Fernando Quesada, "La marea del Pacífico. La Fundación Ford en Chile (1963-1973)", en Fernanda Beigel (ed.) Autonomía y dependencia académica. Universidad e investigación científica en un circuito periférico: Chile y Argentina (1950-1980), Buenos Aires, Editorial Biblos, 2010, 89-101.

${ }^{12}$ Por ejemplo, el apoyo financiero de la Fundación Ford fue muy importante en aquel contexto de la Guerra Fría para que se acometieran investigaciones y estudios sobre aspectos sociales, económicos y políticos del desarrollo en la región a partir, fundamentalmente, del Instituto Latinoamericano de Planificación Económica y Social (ILPES), creado en Santiago de Chile en 1962 bajo la égida de la Comisión Económica para América Latina y el Caribe de las Naciones Unidas (CEPAL). Rolando Franco, La invención del ILPES, Naciones Unidas, CEPAL, Santiago de Chile, 2013.

${ }^{13}$ Fundación Ford, “40 años en la región andina y Cono Sur”, Santiago de Chile, Fundación Ford, 2003,17 y 95.
} 
personas ${ }^{14}$. Si bien, en 1965, saldría a la luz un programa de investigación que provocó un verdadero escándalo en la academia, en la política y en la opinión pública del país, conocido como Proyecto Camelot, que profundizó el descrédito en la región hacia la política externa de Estados Unidos ${ }^{15}$. Este programa, diseñado para medir, predecir y controlar conflictos internos tendientes a la desestabilización social de países de la periferia, nació en la Special Operattions Office perteneciente a la American University, y fue contratado por el Departamento de Defensa de Estados Unidos para ser aplicado en Chile. La denuncia del Camelot fue hecha por Johan Galtung, profesor noruego quien entonces desempeñaba labores de capacitación en la FLACSO de Santiago. Este suceso generó una imagen de desconfianza y de rechazo hacia las fundaciones estadounidenses, hacia sus representantes y sus donaciones. También demuestra, en cambio, la capacidad de autonomía y de incidencia pública que tenían en ese entonces las ciencias sociales chilenas.

A pesar de ese recelo, la Fundación Ford siguió operando en Chile, principalmente porque el gobierno de Eduardo Frei fue afín a los postulados desarrollistas y modernizadores de esta institución filantrópica y de la Alianza para el Progreso, en cuanto a la necesidad de poner en marcha reformas económicas y sociales, como la promoción popular o la reforma agraria, que beneficiasen a los sectores históricamente más desfavorecidos. ${ }^{16}$ En ese sentido, la Fundación Ford continuó financiando proyectos y centros de investigación, como sus diplomáticos académicos prosiguieron manteniendo un rico cuerpo de redes y lazos personales con los científicos sociales que recibían becas y donaciones. Una habitual forma de operar y de cuidar estos contactos, como de evaluar los programas financiados, fue a partir de reuniones periódicas con estos beneficiarios. Los encuentros eran informados y reportados a las autoridades de la Fundación a través de documentos institucionales en los cuales se agregaban, aparte de los pertinentes avances de los proyectos, análisis políticos coyunturales y la revisión de la prensa nacional. Es por esto que resulta pertinente, una vez acaecido el Golpe de Estado el 11 de septiembre de 1973, llevar a cabo un examen de esta documentación, en busca de las voces allí presentes que logran retratar el estado de las universidades y de las ciencias sociales en general. Pero esta evaluación nos va a permitir, además y como decíamos anteriormente, establecer una suerte de espejo como metáfora contenedora de varias dimensiones: la proyección de unos agentes extranjeros de la Fundación Ford traumados y preocupados por el Golpe de Estado, y la imagen formada a partir de los testimonios de académicos y profesores universitarios de un país, si cabe, que provoca vértigo, horror y pánico.

14 Fernanda Beigel, "La institucionalización de las ciencias sociales en América Latina: entre la autonomía y la dependencia académica", en Fernanda Beigel (dir.) Autonomía y dependencia académica. Universidad e investigación científica en un circuito periférico: Chile y Argentina (1950-1980), Buenos Aires, Editorial Biblos, 2010, 89-101.

15 Juan José Navarro y Fernando Quesada, "El proyecto Camelot (1964-1965). La dependencia académica, entre el escándalo y el mito", en Fernanda Beigel (ed.) Autonomía y dependencia académica. Universidad e investigación científica en un circuito periférico: Chile y Argentina (1950-1980), Buenos Aires, Editorial Biblos, 2010,145-167.

${ }^{16}$ Benedetta Calandra, "De la selva brasileña a la capital de las ciencias sociales: proyectos modernizadores de la Fundación Ford en América, Latina, 1927-1965”, Historia y Política, 2015, № 34, 53-80. 


\section{El Golpe a las universidades visto por los agentes de la Fundación Ford.}

La alianza golpista civil y militar afectó a toda la sociedad chilena. Sus efectos llegaron hasta las entrañas de las universidades, las que conformaban entonces un cuerpo institucional fuerte, respetado y protegido. ${ }^{17}$ Por supuesto, las consecuencias también se sintieron en la oficina que la Fundación Ford tenía en Santiago de Chile. ${ }^{18}$ Los nuevos, aunque espurios, gobernantes nacionales fueron conscientes tempranamente de la importancia que suponía la intervención universitaria: se trataba de borrar los valores ligados al desarrollismo social y político. Ejecutado el Golpe de Estado, se activó un plan de desarticulación violenta de las universidades, el cual no contaba con un propósito posterior que lo trascendiera, y que generó un clima de incertidumbre y miedo entre los dirigentes, académicos, profesores y estudiantes.

Precisamente la revisión de cartas, documentos y reportes de los agentes de la Fundación Ford, que incluyen sus impresiones y análisis junto al escrutinio de la prensa nacional además de los testimonios de los principales actores universitarios, logran reflejar aquella realidad como también consiguen diagramar la pluralidad de experiencias y opiniones que este trágico hecho histórico generó. Por ejemplo, en un informe del 20 de septiembre, Peter D. Bell, representante en ese entonces de la Fundación Ford en Chile, relata una entrevista realizada a dos profesores de la Facultad de Ciencias de la Universidad de Chile. ${ }^{19}$ Ellos explican que siete de los trece campus de esta casa de estudios tenían inclinación hacia la Unidad Popular, los cuales ahora serían "reestructurados" por las nuevas autoridades. El contexto de profunda incertidumbre queda sucintamente retratado en un testimonio presente en dicho informe:

En consecuencia, los profesores están sentados de brazos cruzados en el sol de septiembre y tratando de comprender qué ha ocurrido y qué será del futuro. Porque todo el mundo tiene contrato por un año, muchos temen que puedan perder sus puestos. Como esta misma mañana, seis profesores extranjeros y dos estudiantes de grado habían buscado asilo en las embajadas. ${ }^{20}$

\footnotetext{
${ }^{17}$ Un examen exhaustivo de la situación de las universidades chilenas luego del golpe militar de 1973 se encuentra en Manuel Antonio Garretón y Hernán Pozo, "Las universidades chilenas y los derechos humanos", Documento de Trabajo no 213, Programa FLACSO, 1984, Santiago de Chile.

${ }^{18}$ En ese año de 1973 los agentes que trabajan en la oficina de la Fundación Ford de Santiago de Chile y operaban por todo el territorio nacional eran: Peter D. Bell como representante; Peter Hakim como representante auxiliar; Gary N. Horlick como representante auxiliar; Nitas R. Manitzas como consejera del programa; Thomas F. McCarthy como asistente del programa; y Jeffrey M. Puryear como asistente del programa. Ford Foundation Annual Report, Nueva York, Fundación Ford, 1973, 95.

${ }^{19}$ Documento interno de Peter D. Bell. "Faculty of Sciences, University of Chile" (PA 65-327G). 20 de septiembre de 1973. Rockefeller Archive Center (Nueva York). Ford Foundation records. Latin American and the Caribbean Program on the 1973 Coup D'Etat in Chile. Series 1. Box 1. Folder 2, Sep. 12-Sep $28,1973$.

${ }^{20}$ Documento interno de Peter D. Bell "Faculty of Sciences, University of Chile" (PA 65-327G). 20 de septiembre de 1973. Rockefeller Archive Center (Nueva York). Ford Foundation records. Latin American and the Caribbean Program on the 1973 Coup D'Etat in Chile. Series 1. Box 1. Folder 2, Sep. 12-Sep $28,1973$.
} 
En una entrevista a Edgardo Boeninger, rector de la Universidad de Chile, publicada por el diario La Tercera ese mismo 20 de septiembre, se registra una intensa actividad al interior de esa casa de estudios, luego de que el gobierno le encargara llevar a cabo tareas de reestructuración. Según sus palabras: "Se trata en primer lugar de normalizar y poner en marcha la Universidad lo antes posible, para lo cual deberemos reemplazar a las autoridades que de hecho hicieron abandono de sus puestos, y de reemplazar a otras que deberán hacer dejación de sus cargos". ${ }^{21}$ En la práctica, el rector Boeninger debió lidiar con la presión interventora de la dictadura civil-militar y la puesta en marcha de una "limpieza ideológica" al interior de todas las universidades del país. Esta purga se materializó, como una pequeña muestra, en el despido de más de mil académicos sólo en la Universidad de Chile y en la Universidad Católica, de los cuales cerca de 255 provenían de las ciencias sociales ${ }^{22}$. A las expulsiones de los académicos, se sumaba la prohibición de contratar profesores, para evitar la recepción de agentes expulsados por motivos políticos.

Muchos académicos, estudiantes y profesores vivieron episodios de violencia, represión e invasión de su privacidad por los constantes allanamientos. Se instaló el miedo. Esa angustiosa emoción caracteriza una carta fechada el 21 de septiembre que dirige el investigador estadounidense Joseph Tome, que se encontraba en Chile trabajando en aspectos legales de la Reforma Agraria, a Peter D. Bell. ${ }^{23}$ Buscando la ayuda y un cierto consuelo en este agente de la Fundación Ford, Tome relata que se vivía un clima sofocante de inseguridad y sospecha, en el que los extranjeros eran continuamente denunciados y atacados con recelo. Se muestra profundamente consternado y asustado. Acusa también que uno de sus colaboradores ha sido detenido y no tiene mayor información de él. Sus palabras son lapidarias. Escuchemos su voz:

En resumen, las presentes condiciones en Chile hacen casi imposible conducir cualquier tipo de investigación, al menos en las ciencias sociales. Existe un clima psicológico de inseguridad y un ambiente de "anti-intelectualismo" desde el gobierno. En específico, no recomiendo ningún tipo de investigación, especialmente extranjera. Hay mucho miedo, inseguridad y los extranjeros son tratados como sospechosos. Aunque quizás la situación mejore durante los próximos meses y haya un clima más estable y seguro una vez que el régimen militar logre afianzarse. ${ }^{24}$

${ }^{21}$ Diario La Tercera, 20 de septiembre de 1973.

${ }^{22}$ Manuel Antonio Garretón, Las ciencias sociales en la trama de Chile y América Latina, Santiago de Chile, LOM, 2014, 35.

${ }^{23}$ Carta de Joseph Tome a Peter D. Bell. 21 de septiembre de 1973. Rockefeller Archive Center (Nueva York). Ford Foundation records. Latin American and the Caribbean Program on the 1973 Coup D'Etat in Chile. Series 1. Box 1. Folder 2, Sep. 12-Sep 28, 1973.

${ }^{24}$ Carta de Joseph Tome a Peter D. Bell. 21 de septiembre de 1973. Rockefeller Archive Center (Nueva York). Ford Foundation records. Latin American and the Caribbean Program on the 1973 Coup D'Etat in Chile. Series 1. Box 1. Folder 2, Sep. 12-Sep 28, 1973. 
En regiones el clima no era distinto. El periódico El Mercurio titulaba en su edición del sábado 22 de septiembre que se iba a vivir una "reorganización total" en la Universidad de Concepción. Por su parte, Peter Hakim, representante auxiliar de la Fundación Ford en Santiago, le informaba a Peter D. Bell el 25 de septiembre de que varias sedes regionales de la Universidad de Chile habían sido intervenidas por las autoridades militares y que varios rectores, recientemente electos, habían sido invalidados y despedidos. ${ }^{25}$ Un día más tarde, Hakim volvía a redactar otro informe para Bell anunciándole esta vez de que siete centros y departamentos de la Universidad Católica iban a ser reestructurados, mientras que el rector de la Universidad Católica de Valparaíso había sido reemplazado por un ex oficial de la Armada con el mandato de reorganizar la institución. ${ }^{26}$

Esta revisión abreviada de la documentación de los oficiales de la Fundación Ford destinados en Chile logra contextualizar la situación de las universidades y de sus estudiantes y profesores días después del Golpe de Estado. Ante todo, el temor y la incertidumbre inundaban el clima académico. Las violentas y represivas intervenciones de la dictadura remitían a una espera tensa y llena de miedo. Los extranjeros, por su parte, eran víctimas de discriminación arbitraria por partida doble: tanto por provenir del exterior como por su condición intelectual. La desarticulación violenta del ámbito universitario atacaría con especial fuerza a las ciencias sociales.

\section{La desarticulación violenta de las ciencias sociales}

La vida académica y universitaria chilena quedó muy marcada, como estamos viendo, por los sucesos del 11 de septiembre de 1973. El control de la educación, de la enseñanza y del libre pensamiento es una práctica habitual de todo régimen autoritario. La estrategia inicial de los golpistas respecto a las ciencias sociales y a la sociología, no fue otra que desarticularlas con el uso de la violencia. A estas disciplinas las acusaban de socialistas y más concretamente de marxistas (recordemos pues que el Golpe de Estado se autocalificó como "movimiento de liberación nacional contra el yugo marxista"). En consecuencia, el gobierno militar cerró el CESO y la Facultad de Ciencias Políticas de la Universidad de Chile, el CEREN de la Universidad Católica de Chile, el Instituto de Sociología de la Universidad de Concepción, y fueron intervenidos la Universidad Técnica del Estado, hoy Universidad de Santiago de Chile, y el Instituto de Sociología de la Universidad Católica de Chile. $^{27}$

\footnotetext{
${ }^{25}$ Documento interno de Peter Hakim a Peter D. Bell. 25 de septiembre de 1973. Rockefeller Archive Center (Nueva York). Ford Foundation records. Latin American and the Caribbean Program on the 1973 Coup D'Etat in Chile. Series 1. Box 1. Folder 2, Sep. 12-Sep 28, 1973.

${ }^{26}$ Documento interno de Peter Hakim a Peter D. Bell. 26 de septiembre de 1973. Rockefeller Archive Center (Nueva York). Ford Foundation records. Latin American and the Caribbean Program on the 1973 Coup D'Etat in Chile. Series 1. Box 1. Folder 2, Sep. 12-Sep 28, 1973.

27 Recordemos aquí brevemente que en 1961 se creó el Centro de Estudios Socioeconómicos (CESO), fundado en la Universidad de Chile por Eduardo Hamuy, quien ya había dirigido el Instituto de Investigaciones Sociológicas de la Facultad de Filosofía y Educación. En los años 70 el CESO aglutinó importantes teóricos de la dependencia como Theotonio dos Santos, Vania Bambirra, Orlando Caputo o
} 
A partir de ese momento, numerosos científicos sociales chilenos, latinoamericanos y extranjeros "fueron tratados con hostilidad" ${ }^{28}$, se vieron expulsados de sus puestos de trabajo, sufrieron torturas, persecuciones, vejaciones e incluso algunos pagaron con su vida los desmanes autoritarios. Los informes y la correspondencia entre los agentes de la Fundación Ford recogen sucintamente ese clima violento y de persecución desmedida. Son crónicas, también, de la cara más represiva de la incipiente dictadura civil-militar y de la sostenida política de violación de derechos humanos que acometió. Así, por ejemplo, Nita Manitzas, remitió varios informes con fecha del 21 de septiembre a Peter D. Bell acerca de distintos centros e institutos de la Universidad Católica. El primero de ellos versaba sobre la situación del Instituto de Sociología. ${ }^{29}$ En esas páginas relata que se había reunido con el director, y que ambos estaban de acuerdo en congelar la donación de la Fundación Ford hasta que el clima fuese más claro. Aunque era muy probable que el Instituto fuese prontamente intervenido, como así finalmente sucedió.

Además, en la voz del director se apreciaba, aparte de esa sensación de incertidumbre, una acción de auto-censura como estrategia de supervivencia. En concreto reconocía la necesidad de modificar el currículo de las asignaturas y carreras del Instituto de Sociología. Decía así: "Con seguridad partes del currículo necesitarán ser revisadas, pero el director cree que esto puede realizarse sin muchos perjuicios para el núcleo básico de la actividad científica. Una mayor preocupación para él es si la sociología será factible como carrera profesional en los próximos años". ${ }^{30}$ Se observa, en consecuencia, cómo dentro de la Universidad Católica estaban muy preocupados también por la viabilidad de la sociología como carrera. Además, en ese informe Manitzas añadía, siguiendo la opinión del director,

Sergio Pizarro. El Centro de Estudios de la Realidad Nacional (CEREN), inaugurado en la Universidad Católica a finales de los años 60, formó a una joven generación de sociólogos chilenos, como José Joaquín Brunner o Manuel Antonio Garretón. Mientras que en la Universidad de Concepción se estableció en esos años el Instituto Central de Sociología, fundado por el profesor Raúl Samuel y que posteriormente sería reorganizado por Guillermo Briones. Juan Jesús Morales, “José Medina Echavarría y la sociología en Chile. El intento de constituir una "tradición sociológica" en la Escuela Latinoamericana de Sociología", Revista Central de Sociología, No 7, 2012, 79-115; Rolando Franco, La FLACSO clásica (1957-1973). Vicisitudes de las Ciencias Sociales latinoamericanas, Santiago de Chile, FLACSO, Catalonia, 2007, 37-38; José Joaquín Brunner, El caso de la sociología en Chile: formación de una disciplina, Santiago de Chile, FLACSO, 222.

28 José Joaquín Brunner, "La participación de los centros académicos privados en el desarrollo de las ciencias sociales", Documentos de Trabajo, N²57, Santiago de Chile, 1985, 10.

${ }^{29}$ El Instituto de Sociología de la Universidad Católica había sido fundando en 1958 y dirigido por el padre belga Roger Vekemans. Se puso en marcha como un medio para poner en práctica la doctrina social de la Iglesia, puesto que "también en los ambientes católicos se sintió la necesidad de disponer de una herramienta científica para abordar los apremiantes problemas sociales". En 1961 se creó el Instituto de Investigaciones Sociológicas de la Universidad Católica para dar cuerpo a los estudios empíricos del Instituto de Sociología. Ricardo Krebs, Historia de la Pontificia Universidad Católica de Chile: 1888-1988, Santiago de Chile: Ediciones Universidad Católica de Chile, 1994, 537.

${ }^{30}$ Informe de Nitas R. Manitzas a Peter D. Bell. "Pontifical Catholic University of Chile, Institute of Sociology" (PA64-452). 21 de septiembre de 1973. Rockefeller Archive Center (Nueva York). Ford Foundation records. Latin American and the Caribbean Program on the 1973 Coup D'Etat in Chile. Series 1. Box 1. Folder 2, Sep. 12-Sep 28, 1973. 
que muy probablemente "tanto las investigaciones como los trabajos de campo sean suspendidos de forma indefinida".

En el siguiente informe Manitzas da cuenta a Bell de la situación del Centro de Desarrollo Urbano y Rural de la Universidad Católica. ${ }^{31}$ Informa de que hay una persona del centro arrestada, de nacionalidad uruguaya. No hay más datos sobre este suceso. Si bien, la funcionaria de la Fundación Ford recoge la opinión del director sobre la intervención militar: saben que deberán cambiar el enfoque de su trabajo, pasando desde propuestas para apuntalar el "desarrollo social urbano y regional" hacia un trabajo de "planificación más técnica". Vemos, una vez más, cómo una de las actitudes comunes ante las previsibles medidas de la dictadura era el cambio de registro y la asunción de un nuevo vocabulario menos político, menos ideologizado y más técnico. Al mismo tiempo, en ese informe -como objeto de representación de esos sucesos históricos- el director afirmaba estar seguro que el rol de la Democracia Cristiana y de la Iglesia (especialmente a partir de la figura del Cardenal Silva Henríquez) ayudaría a preservar y mantener la integridad de la Universidad Católica.

Justamente el otro informe de Manitzas dirigido a Bell el 21 de septiembre, y dedicado al Instituto de Ciencias Políticas de la Universidad Católica, recoge de forma sintética las tensiones internas que se estaban viviendo dentro de esa casa de estudios. A pesar de que los académicos y el personal estaban de vuelta al trabajo, se estaba discutiendo arduamente sobre el panorama de aquel presente. De hecho, había una disputa entre la Democracia Cristiana y los gremialistas por la dirección del Instituto y por toda la Universidad a la hora de "realizar purgas de las personas del staff", decía el informe. ${ }^{32}$ No obstante dos miembros del Instituto habían sido arrestados por el régimen (uno de ellos sabemos que era Carlos Naudon). ${ }^{33}$ Asimismo, el profesor visitante norteamericano David Cussack - becado también por la Fundación Ford- había sufrido el allanamiento de su casa y había sido detenido e interrogado durante algunas horas. Dicho documento refleja, una vez más, la impresión de que para su supervivencia el Instituto debería tener que eliminar algunos cursos y asignaturas de su currículo. Al igual que este informe citaba que varios académicos y profesores estaban pensando en emigrar hacia los Estados Unidos.

El camino del exilio fue una opción que, al final, terminó de imponerse para muchos académicos y científicos sociales perseguidos por el régimen militar una vez que la

\footnotetext{
${ }^{31}$ Informe de Nitas R. Manitzas a Peter D. Bell. "Pontifical Catholic University of Chile, Center for Urban and Regional Development" (PA 66-30C). 21 de septiembre de 1973. Rockefeller Archive Center (Nueva York). Ford Foundation records. Latin American and the Caribbean Program on the 1973 Coup D'Etat in Chile. Series 1. Box 1. Folder 2, Sep. 12-Sep 28, 1973.

${ }^{32}$ Informe de Nitas R. Manitzas a Peter D. Bell. "Pontifical Catholic University of Chile, Institute of Political Science" (PA 72-59). 21 de septiembre de 1973. Rockefeller Archive Center (Nueva York). Ford Foundation records. Latin American and the Caribbean Program on the 1973 Coup D'Etat in Chile. Series 1. Box 1. Folder 2, Sep. 12-Sep 28, 1973.

${ }^{33}$ Carlos Naudon se había encargado de la edición de un libro colectivo, titulado América 70 y publicado en 1970 por el Instituto de Ciencias Políticas de la Universidad Católica, en el que participaron científicos sociales como Gonzalo Arroyo, Claudio Veliz, Osvaldo Sunkel o Jacques Chonchol. El objetivo de ese estudio fue proponer una reflexión desde diferentes disciplinas sobre las posibilidades de dar fin a la dependencia exterior de Chile y de América Latina.
} 
represión se instaló y se tornó rutinaria e insoportable para un buen número de departamentos, escuelas o instituciones. Uno de los organismos que más padeció este violento y permanente control gubernamental fue la FLACSO. ${ }^{34}$ Precisamente un memorándum de la Fundación Ford, fechado el día 24 de septiembre, recoge varios hechos trágicos que sufrieron los alumnos y el personal académico de esta institución. Así, por ejemplo, el profesor Joaquín Duque, de la Escuela de Sociología, fue arrestado en su casa el día 11 de septiembre y no se sabía nada de él después de dos semanas. Tres estudiantes de la FLACSO estaban detenidos en el Estadio Nacional. Un cuarto estudiante, de Nicaragua, ya liberado, declaró haber sido golpeado y cortado. Otro alumno boliviano también fue apresado y su casa allanada. Terminó siendo brutalmente asesinado. El siguiente extracto del informe recoge la dramática secuencia de esos hechos:

Un estudiante boliviano, que se encontraba estudiando en la Escuela de Ciencia Política de la FLACSO con una beca del Banco Interamericano para el Desarrollo, fue arrestado en su casa a principios de esta semana. La casa fue allanada con la presencia de su mujer. No se encontraron ningunas armas. El personal de la UNESCO hizo una protesta formal ante la Oficina de Asuntos Exteriores y se les aseguró que el estudiante sería puesto en libertad. Después su mujer recibió una llamada anónima informándola de que podía recoger el cuerpo de su marido en la morgue. Un experto de la UNESCO fue a la morgue y, después de examinar 180 cuerpos, identificó al estudiante. Por la naturaleza de las heridas, el experto de la UNESCO cree que este estudiante y los otros muertos fueron ejecutados ya sea con ametralladoras o con una granada de mano. ${ }^{35}$

Pocas palabras más se pueden añadir ante tal escena. Vistos estos hechos, y dada la represión de la dictadura civil-militar sobre los estudiantes y los profesores de la FLACSO, los directores de este organismo regional llegaron a la conclusión de que no podían seguir

\footnotetext{
${ }^{34}$ Es pertinente señalar aquí que la Facultad Latinoamericana de Ciencias Sociales (FLACSO) se creó en 1957 por un acuerdo de la UNESCO y de los gobiernos latinoamericanos a la hora de proveer a la región un centro de investigación y de enseñanza de ciencias sociales, a semejanza del Centro de Investigaciones sobre los Problemas del Desarrollo Económico y Social en el Asia Meridional de Nueva Delhi. Gracias a la insistencia del gobierno chileno y de la Universidad de Chile se radicó en Santiago. La FLACSO primero puso en funcionamiento en ese mismo año de 1957 la Escuela Latinoamericana de Sociología (ELAS), que representó en aquellos días un proyecto académico innovador para el campo universitario chileno al ofrecer un postgrado de sociología antes de que hubiera carreras de sociología en las universidades del país. Años más tarde, en 1964, se crearía la Escuela Latinoamericana de Ciencia Política y Administración Pública (ELACP) al calor de la expansión de las ciencias sociales nacionales y latinoamericanas. Rolando Franco, La FLACSO clásica (1957-1973). Vicisitudes de las Ciencias Sociales latinoamericanas, Santiago de Chile, FLACSO, Catalonia, 2007, 29.

35 Informe "Latin American Faculty of Social Sciences" (PA 68-796B). 24 de septiembre de 1973. Rockefeller Archive Center (Nueva York). Ford Foundation records. Latin American and the Caribbean Program on the 1973 Coup D'Etat in Chile. Series 1. Box 1. Folder 2, Sep. 12-Sep 28, 1973.
} 
funcionando en Chile. En ese momento comenzaron a evaluar la posibilidad de trasladar la oficina a otro país latinoamericano, creándose finalmente en el año 1974 el Programa Buenos Aires de la FLACSO, el cual recibió a numerosos académicos y estudiantes que escapaban de esa virulenta situación ${ }^{36}$. Otros organismos internacionales, que habían sido baluartes para el desarrollo y la institucionalización de las ciencias sociales en Chile y en toda América Latina, como la CEPAL o el ILPES, ayudaron también a salir del país a muchos estudiantes y profesores acusados de subversión. ${ }^{37}$ Estos centros, siguiendo su tradición democrática, no abdicarían después de su "vocación crítica" respecto al gobierno militar. Incluso la CEPAL y su pensamiento democrático, heterodoxo, estructuralista y latinoamericano, fue perseguido por la dictadura del general Pinochet, asesinando de forma muy vil a Carmelo Soria el 14 de julio de $1976 .{ }^{38}$ Fue un toque de atención a los funcionarios de este organismo internacional y a todos los científicos sociales del país. Fue también, por supuesto, un aviso contra todo pensamiento crítico.

\section{Desarticulación de las ciencias sociales y tecnificación económica}

Iniciada la estrategia de desarticulación de las ciencias sociales por parte de la dictadura civil-militar, la persecución fue profundizándose, siendo éstas jibarizadas y desplazadas de las universidades. A la par, la economía en su vertiente monetarista y neoliberal fue llenando el intersticio dejado por las ciencias sociales y se fue instalando en la nueva burocracia autoritaria, dada la necesidad de un plan económico que lo acompañara. Se cuestionó entonces la perspectiva reformista de procesar el desarrollo en Chile, la cual trataba de unir programas económicos con estrategias de planificación y mejorar social. Al interior de las Fuerzas Armadas y del cuerpo civil que encabezaron el Golpe, existían voces disidentes respecto a la naturaleza de la conducción socioeconómica que el régimen militar habría de impulsar. Por un lado, los militares clásicos de corte desarrollista se inclinaban por un amplio control estatal de la economía. Por contrapartida, y alojado principalmente en la Armada, otro grupo se mostraba proclive a una reorganización monetarista. Este grupo estaba sujeto al influjo de los economistas de la Universidad Católica. ${ }^{39}$

\footnotetext{
36 Víctor Algarañaz, "Between scientific autonomy and academic dependency: Private Research Institutes under dictatorship in Argentina (1976-1983). The case of FLACSO”, Fernanda Beigel (ed.), The Politics of Academic Autonomy in Latin América, Londres, Ashgate, 2013, 249-263.

${ }^{37}$ Recordemos brevemente que la División de Planificación Social del ILPES fue decisiva para la evolución del pensamiento sociológico latinoamericano. Dirigida desde 1963 por el sociólogo del exilio español José Medina Echavarría, allí se formó un nutrido grupo de investigación en el que destacaron, entre otros nombres, el chileno Enzo Faletto y el brasileño Fernando H. Cardoso, quienes en 1969 publicarían el clásico Dependencia y desarrollo en América Latina.

${ }^{38}$ Carmelo Soria era un español que se había exiliado a Chile tras la Guerra Civil y que trabajaba en las Naciones Unidas, como funcionario de la CEPAL. Era nieto del ingeniero Arturo Soria y hermano de Arturo Soria, quien en Chile había fundado la editorial Cruz del Sur, publicación que reunió a intelectuales del exilio español. Javier Malagón, “Cómo recibió América al exilio español”, en Charo Portela Yáñez (ed.), Cincuenta años de exilio español en Puerto Rico y el Caribe 1939-1989, La Coruña, Edicios Do Castro, 1991, 35.

${ }^{39}$ Carlos Huneeus, El régimen de Pinochet, Santiago de Chile, Taurus, 2016; Verónica Valdivia, El golpe después del golpe. Leigh vs. Pinochet. Chile 1960-1980, Santiago de Chile, LOM, 2003.
} 
Estos economistas, conocidos como los "Chicago Boys" por estudiar en aquella universidad estadounidense, habían regresado a Chile convencidos de que la liberación de los mercados representaba un nuevo modelo de desarrollo económico. ${ }^{40}$ Se buscaba, por un lado, un antídoto contra las políticas económicas y sociales propuestas por la CEPAL para América Latina y también rechazar la perspectiva de la dependencia y su cuestionamiento al sistema capitalista. Además, se perseguía desde la Universidad Católica rivalizar con los estudios económicos de la Universidad de Chile, vistos como proyectos económicos de inclinación cepalina, potilitizados y de carácter populista. Junto con esta pretensión de incidir en el ámbito académico apelando a la rigurosidad técnica y científica, los "Chicago Boys" querían experimentar in situ las teorías referidas al capital humano concebidas por la Escuela de Economía dirigida por Milton Friedman, George Stigler y Gary Becker. Como "un nuevo tipo de élite tecnocrática" ${ }^{41}$, poco les importó las políticas represivas mientras se respetasen las bases fundamentales del orden económico. Incluso entre estos economistas neoliberales hubo una creencia que afirmaba "una relación estrecha entre el desarrollo económico y el autoritarismo y que éste constituye una condición de aquél" 42.

Justamente Lovell Jarvis, asesor del programa económico del Cono Sur de la Fundación Ford y radicado entonces en Santiago, escribió un memorándum a Peter D. Bell el 21 de septiembre en el que se refleja esta colaboración civil con la construcción del programa económico de la dictadura. En él retrata la entrevista que sostuvo con Dominique Hachette, quien en ese entonces oficiaba como director del Instituto de Economía de la Universidad Católica. Hachette expresaba que "el único miembro del Instituto que aparentemente dejará su puesto para una posición en el gobierno es Sergio de Castro. Él estaba profundamente involucrado en el desarrollo del plan económico que siendo ahora

${ }^{40}$ El 30 de marzo de 1956 se había firmado un convenio de cooperación académica entre la Universidad de Chicago, la Administración para la Cooperación Internacional del gobierno estadounidense y la Universidad Católica, vinculándose las Facultades de Economía de estas dos universidades. El contrato estipulaba una colaboración de tres años, pero se extendió hasta 1964. Sergio de Castro, uno de los primeros beneficiados por este programa de becas, asumió el decanato de la Facultad de Economía de la Universidad Católica introduciendo una nueva orientación de los estudios económicos. Estos becarios se encargarían después de hacer toda la revolución macroeconómica del gobierno militar, ocupando diversos puestos en los Ministerios de Economía, Trabajo y en el de Hacienda y destacando los nombres de Pablo Baraona, Álvaro Bardón, Jorge Cauas, Sergio de Castro, Fernando Lens, Rolf Lüders, Sergio Undurraga, Juan Villarzú o José Luis Zavala. Posteriormente colaborarían Hernán Buchi, Julio Dittborn, Joaquín Lavín o José Piñera. Manuel Gárate Chateau, La revolución capitalista en Chile (1973-2003), Santiago de Chile, Ediciones Universidad Alberto Hurtado, 2012; Francisco Rosende (ed.), La Escuela de Chicago. Una mirada histórica a 50 años del convenio Chicago/Universidad Católica. Ensayos en honor a Arnold C. Harberger, Santiago de Chile, Ediciones Universidad Católica de Chile, 2007; Juan Gabriel Valdés, La Escuela de Chicago. Operación Chile. Buenos Aires, Editorial Zeta, 1989; Pilar Vergara, Auge y caída del neoliberalismo en Chile. Santiago de Chile, FLACSO, 1985.

41 Enzo Faletto, "De la teoría de la dependencia al proyecto neoliberal: el caso chileno", Revista de Sociología, $N^{\circ}$ 13, Santiago, Departamento de Sociología, Facultad de Ciencias Sociales de la Universidad de Chile, 1999, 133.

${ }^{42}$ Aldo Solari; Rolando Franco, Joel Jutkowitz, Teoría, acción social y desarrollo en América Latina, México D.F., Siglo XXI, 1976. 
presentado al gobierno por el Partido Nacional."43 Respecto al futuro del país, el economista francés era pesimista. Él creía que el gobierno iba a adoptar un plan económico muy conservador y una política restrictiva que serían muy severas con la sociedad chilena. El tiempo le concedió la razón con este presagio. En el mismo documento, Sergio Molina, alto personero de la Democracia Cristiana, también es entrevistado en atención a que se encontraba vinculado al Instituto. A él le fue ofrecido el cargo de Subsecretario de Economía, el cual rechazó. Su estrategia, y la de su partido, era la de instalar técnicos en posiciones intermedias, evitando la responsabilidad directa del accionar autoritario y, en palabras de Molina, ser "descabezados".44

Fueron días agitados para el asesor Lovell Jarvis. Respondiendo a su condición de diplomático académico, y en aras de mantener activas las redes creadas por la Fundación Ford y saber qué pasaba con los beneficiarios de sus donaciones, también sostuvo una entrevista con Álvaro Bardón, director del Departamento de Economía de la Universidad de Chile. Bardón le informó sobre los becarios extranjeros del Departamento, quienes fueron víctimas de violencia y fueron arrestados por Carabineros, como fue el caso del científico social y economista desarrollista y dependentista Pedro Paz. ${ }^{45}$ En el memorándum que da cuenta de esta entrevista, con fecha 21 de septiembre, también se consigna que el Departamento, con la mayoría de sus miembros democratacristianos, no ha entrado al gobierno. ${ }^{46}$ Finalmente, Bardón es pesimista respecto a la estructura económica gubernamental naciente, al opinar que carecen de habilidades técnicas y se sitúan en la "extrema derecha económica".

El contraste entre el Instituto de Economía de la Universidad Católica y el Departamento de Economía de la Universidad de Chile se hace claro. Mientras que estos últimos son víctimas de violencia de Estado y están lejos de ser considerados como partícipes del gobierno, en atención a su orientación estructuralista, en la Universidad Católica las clases seguían funcionando y gozaban de normalidad. Adicionalmente, sus académicos y dirigentes eran invitados y propuestos a formar parte de la conducción económica de la dictadura. Si bien dentro de esa casa de estudios y dentro de la propia disciplina económica hubo voces críticas que también aparecen recogidas en la

\footnotetext{
43 Informe de Lovell Jarvis a Peter Bell. "Current Situation in the Institute of Economics, Catholic University”. 21 de septiembre de 1973. Rockefeller Archive Center (Nueva York). Ford Foundation records. Latin American and the Caribbean Program on the 1973 Coup D'Etat in Chile. Series 1. Box 1. Folder 2, Sep. 12-Sep 28, 1973.

44 Informe de Lovell Jarvis a Peter Bell. "Current Situation in the Institute of Economics, Catholic University”. 21 de septiembre de 1973. Rockefeller Archive Center (Nueva York). Ford Foundation records. Latin American and the Caribbean Program on the 1973 Coup D'Etat in Chile. Series 1. Box 1. Folder 2, Sep. 12-Sep 28, 1973.

${ }^{45}$ Es oportuno señalar que Pedro Paz había publicado en 1970 junto a Osvaldo Sunkel El subdesarrollo latinoamericano y la teoría del desarrollo, un clásico texto de la teoría de la dependencia.

${ }^{46}$ Informe de Lovell Jarvis a Peter Bell. "Current status of the Departments of Economics. West Campus and Department of Political Economy, North Campus, University of Chile”. 21 de septiembre de 1973. Rockefeller Archive Center (Nueva York). Ford Foundation records. Latin American and the Caribbean Program on the 1973 Coup D'Etat in Chile. Series 1. Box 1. Folder 2, Sep. 12-Sep 28, 1973.
} 
documentación de la Fundación Ford. Era el caso del Centro de Estudios de Planificación Nacional (CEPLAN).

Al momento del Golpe, Alejandro Foxley, su director, se encontraba en Inglaterra y los esfuerzos por contactarlo fueron infructuosos. El asesor Jarvis entrevistó en su lugar a Ricardo Ffrench-Davis, quien sustituía a Foxley. En la entrevista, recogida en un informe del 24 de septiembre, el economista también formado en Chicago manifestó su relativa tranquilidad respecto al futuro del Centro. Si bien era consciente de que "el lenguaje tendrá que ser moderado y nuevos campos de investigación restringidos. En particular, los temas históricos y los problemas técnicos del futuro serán objeto de investigación, en lugar de temas de actualidad de mayor sensibilidad". ${ }^{47}$ Nuevamente aparecía la necesidad de sortear la censura. Además, Ffrench-Davis reconocía las disputas internas dentro del régimen entre las perspectivas desarrollista y monetarista. Por supuesto, auguraba también un oscuro horizonte para las ciencias sociales:

Al discutir sobre las políticas económicas del Régimen ambos están de acuerdo en que son de derechas y que responden principalmente a las propuestas por la SOFOFA y el Partido Nacional. Ffrench-Davis cree que tendrá lugar una disputa por la conducción económica entre esos grupos y los militares, que serían más proclives al ISI. También estima, el economista, que las ciencias sociales serán afectadas muy negativamente por el Golpe. ${ }^{48}$

Por último, la entrevista también sirvió para que Ffrench-Davis se refiriera al futuro de la Universidad Católica y del CEPLAN. En ambos casos se mostraba relativamente optimista, en tanto estimaba que no iban a ser intervenidos drásticamente, mientras que los estudios económicos gozarían de cierta autonomía. Este economista -crítico de la ortodoxia neoliberal - no logró atisbar los acontecimientos inmediatos. ${ }^{49}$ La Universidad Católica fue intervenida duramente mientras que el Centro fue expulsado de esa casa de estudios y tuvo que reorganizarse en 1976 desde el lado privado bajo la fórmula de la actual Corporación de Investigaciones Económicas para Latinoamérica (CIEPLAN).

\footnotetext{
47 Informe de Lovell Jarvis a Peter D. Bell. "Center for National Planning Studies (CEPLAN), Catholic University". 24 de septiembre de 1973. Rockefeller Archive Center (Nueva York). Ford Foundation records. Latin American and the Caribbean Program on the 1973 Coup D’Etat in Chile. Series 1. Box 1. Folder 2, Sep. 12-Sep 28, 1973.

${ }^{48}$ Informe de Lovell Jarvis a Peter D. Bell. "Center for National Planning Studies (CEPLAN), Catholic University”. 24 de septiembre de 1973. Rockefeller Archive Center (Nueva York). Ford Foundation records. Latin American and the Caribbean Program on the 1973 Coup D'Etat in Chile. Series 1. Box 1. Folder 2, Sep. 12-Sep 28, 1973.

${ }^{49}$ Ricardo Ffrench Davis, Entre el neoliberalismo y el crecimiento con equidad, Santiago de Chile, LOM, 2003.
} 


\section{Las consecuencias: exilios, redes de solidaridad y disyuntivas dentro de la Fundación Ford.}

Ante unos representantes de un pensamiento excluyente y de unas fuerzas económicas neoliberales dispuestos a colaborar decididamente con la dictadura, la primera y principal tarea para las ciencias sociales golpeadas fue asegurar la supervivencia de los estudiantes y de los académicos. Para tal fin se organizaron programas de solidaridad y de evacuación al exilio a partir de los organismos regionales e internacionales y de las fundaciones extranjeras que operaban en Chile. De esta forma, se pusieron en marcha acciones de cooperación y auxilio desarrollados, como vimos, por la FLACSO, la CLACSO o la Fundación Ebert ${ }^{50}$. La Fundación Ford también ayudaría en estas actividades. Si bien aquí únicamente nos queremos detener brevemente en la foto inmediata de esos hechos.

Esta institución filantrópica actuó inicialmente como un canal o mediador entre las muestras de solidaridad que provenían de instituciones y de académicos del extranjero y los organismos de ciencias sociales latinoamericanos, especialmente la CLACSO, que comenzaban a poner en marcha sus actividades de auxilio. En este sentido, destaca la carta enviada el 1 de octubre por Clemens Heller, profesor de la Casa de Ciencias del Hombre de París a Marion Bieber, funcionaria de los Asuntos Europeos e Internacionales de la Fundación Ford, en la que confiesa su preocupación ante los eventos que se estaban sucediendo. La misiva decía así:

Nuestra institución está particularmente afectada por los recientes acontecimientos en Chile por nuestra conexión con las instituciones de investigación chilenas, como FLACSO, CIDU, CEREN, CESO, las cuales han sido cerradas. Muchos de nuestros profesores han enseñado allí y varios miembros de esas instituciones han sido formados en París. ${ }^{51}$

El texto anterior ejemplifica, aunque sea en apretada síntesis, lo que habían representado las ciencias sociales chilenas antes del 11 de septiembre en términos de internacionalización, de cosmopolitismo y de capacidad para articular redes intelectuales que terminaron por diseminarse en múltiples espacios académicos y extra-académicos. En relación a esa carta de Heller, Richard W. Dye, subdirector del Programa Latinoamericano de la Fundación Ford y enviado esos días a Santiago de Chile, aconsejaba el 16 de octubre a Bieber que era más conveniente que el profesor francés contactase directamente con la CLACSO en Buenos Aires y con su secretario ejecutivo, Enrique Oteiza, pues era este organismo regional quien se estaba ocupando de los científicos sociales chilenos y

\footnotetext{
50 Paola Bayle "La migración forzosa de una población calificada. El programa de Reubicación de Cientistas Sociales CLACSO y el exilio chileno (1973-1976)", Fernanda Beigel (ed.) Autonomía y dependencia académica. Universidad e investigación científica en un circuito periférico: Chile y Argentina (1950-1980), Buenos Aires, Editorial Biblos, 2010, 233-269.

${ }^{51}$ Carta de Clemens Heller a Marion Bieber. París, 1 de octubre de 1973. Rockefeller Archive Center (Nueva York). Ford Foundation records. Latin American and the Caribbean Program on the 1973 Coup D'Etat in Chile. Series 1. Box 1. Folder 3, Oct. 1 - Oct. 9, 1973.
} 
latinoamericanos. De hecho, en su carta Dye resumió acertadamente los propósitos y los esfuerzos de CLACSO en esas tareas de auxilio y socorro: "1) mantener el mayor número posible de intelectuales para que trabajen productivamente en un emplazamiento latinoamericano y 2) legitimar en la medida que se pueda la selección de personas que necesitan ayuda para su reubicación". 52

Es necesario recordar aquí que desde su fundación en 1966 la CLACSO recibió ayuda financiera y donaciones por parte de la Fundación Ford que permitieron el desarrollo y sostenimiento de actividades, de seminarios o de grupos de investigación. ${ }^{53}$ Este pasado de colaboración común explicaría la fluida cooperación que habría entre estas dos entidades a la hora de atender las demandas de asistencia y que llevaron a la institución filantrópica estadounidense a apoyar el programa de CLACSO dirigido a académicos latinoamericanos forzados a tomar el camino del exilio por motivos políticos ${ }^{54}$. Si bien dentro de la propia institución filantrópica norteamericana hubo en esos días un debate interno a la hora de decidir el destino de su ayuda y sus donaciones bajo aquel contexto autoritario. La incertidumbre caracteriza varias cartas que intercambiaron entre el 24 y el 26 de septiembre Peter D. Bell, David E. Bell, vicepresidente ejecutivo de la Fundación, y William Carmichael, jefe de la Oficina para América Latina y el Caribe en la sede central de Nueva York. Ambos compartían la opinión que las solicitudes de becas y donaciones recibidas antes del Golpe por parte de universidades chilenas estaban ya obsoletas dado el nuevo contexto político y entendían, por tanto, la necesidad de evaluar las donaciones existentes. ${ }^{55}$

En paralelo, se comenzó a discutir seriamente la necesidad o no de permanecer abierta la oficina de Fundación Ford en Chile, más teniendo en cuenta el allanamiento que sufrió en su casa la agente Nitas Manitzas el día 30 de septiembre. En carta del 8 de octubre, Peter D. Bell le escribe a Nathaniel Davis, embajador norteamericano en Santiago, transmitiéndole su inquietud por este hecho y por su visita a Tobías Barrios, director de protocolo del Ministerio de Asuntos Exteriores: "Expresé mi preocupación no sólo porque la casa de Manitzas había sido allanada, sino también porque los soldados se habían llevado

\footnotetext{
${ }^{52}$ Carta de Richard W. Dye a Marion Bieber. Santiago de Chile, 16 de octubre de 1973. Rockefeller Archive Center (Nueva York). Ford Foundation records. Latin American and the Caribbean Program on the 1973 Coup D'Etat in Chile. Series 1. Box 1. Folder 3, Oct. 1 - Oct. 9, 1973.

${ }^{53}$ El Consejo Latinoamericano de Ciencias Sociales (CLACSO) había sido creado en 1966 como "una organización de carácter regional, no gubernamental, que agrupaba a institutos y centros de investigación y docencia en ciencias sociales, con el fin de coordinar las actividades de esos centros". La labor de la CLACSO fue realmente importante a la hora de estrechar vínculos académicos y fomentar la cooperación científica entre académicos, investigadores, profesores, centros y universidades de la región. Paola Bayle, "La migración forzosa de una población calificada. El programa de Reubicación de Cientistas Sociales CLACSO y el exilio chileno (1973-1976)", en Fernanda Beigel (dir.), Autonomía y dependencia académica. Universidad e investigación científica en un circuito periférico: Chile y Argentina (1950-1980), Buenos Aires, Editorial Biblos, 2010, 235.

${ }^{54}$ Fundación Ford, "Ford Foundation Annual Report” Nueva York: Fundación Ford, 1973, 38.

${ }^{55}$ Carta de Peter Bell a William D. Carmichael. 24 de septiembre de 1973. Carta de William D. Carmichael a David E. Bell. 26 de septiembre. Rockefeller Archive Center (Nueva York). Ford Foundation records. Latin American and the Caribbean Program on the 1973 Coup D'Etat in Chile. Series 1. Box 1. Folder 2, Sep. $12-$ Sep 28, 1973.
} 
libros y publicaciones, supuestamente para quemarlas". ${ }^{56}$ Como se puede apreciar, la escalada represiva del régimen ya no respetaba a estos "diplomáticos académicos" estadounidenses que pasaron también a ser objetivos de la política de desarticulación violenta de la vida científica, intelectual y universitaria del país. Este suceso, efectivamente, se vivió con preocupación por parte de las autoridades de la Fundación Ford. Chile era un país central para sus donaciones en América Latina, con una larga tradición, y donde esta institución filantrópica había sido, de una u otra forma, actor de ese laboratorio social durante los últimos años. ${ }^{57}$

William Carmichael escribió y envió el 10 de octubre a varios funcionarios y representantes de la Fundación en América Latina, entre los que se encontraba Peter D. Bell, un memorándum titulado "Regímenes deplorables y Políticas de la Fundación en el extranjero" que daba cuenta de las "recientes discusiones" que habían tenido en el directorio de Nueva York ante el Golpe de Estado del 11 de septiembre. ${ }^{58}$ Al día siguiente el mismo Carmichael remitió a McGeorge Bundy, presidente de la Fundación Ford, y a otros altos directivos una copia de la carta enviada por Peter D. Bell al embajador norteamericano de Santiago sobre el incidente de Nitas Manitzas. ${ }^{59}$ El debate ético interno sobre la intervención o no de la Fundación Ford en regímenes y dictaduras militares ya estaba plenamente instalado. Justamente la carta que envió Kalman Silvert, consejero del Programa Latinoamericano y consultor para las ciencias sociales, a David E. Bell, vicepresidente ejecutivo de la Fundación, con fecha del 18 de octubre es clave para entender la posición que tomaría después esta institución filantrópica en relación a la dictadura civil-militar chilena. ${ }^{60}$ Escuchemos la voz de este profesor norteamericano:

\footnotetext{
${ }^{56}$ Carta de Peter D. Bell a Nathaniel Davis. 8 de octubre de 1973. Rockefeller Archive Center (Nueva York). Ford Foundation records. Latin American and the Caribbean Program on the 1973 Coup D'Etat in Chile. Series 1. Box 1. Folder 3, Oct. 1 - Oct. 9, 1973.

${ }^{57}$ Fernando Quesada, "La marea del Pacífico. La Fundación Ford en Chile (1963-1973)”, en Fernanda Beigel (dir.), Autonomía y dependencia académica. Universidad e investigación científica en un circuito periférico: Chile y Argentina (1950-1980), Buenos Aires, Editorial Biblos, 2010, 89-101.

58 Memorándum de William. D. Carmichael a Peter D. Bell, John H. Funari (representante de México, América Central y el Caribe), Jame R. Himes (representante de Colombia y Venezuela), Stanley A. Nicholson (representante de Brasil) y a James Trowbridge (representante de Perú, Bolivia y Ecuador). "Distatesful Regimes and Foundation Policies Overseas". 10 de octubre de 1973. Rockefeller Archive Center (Nueva York). Ford Foundation records. Latin American and the Caribbean Program on the 1973 Coup D'Etat in Chile. Series 1. Box 1. Folder 3, Oct. 1 - Oct. 9, 1973.

${ }^{59}$ Carta de William D. Carmichael a McGeorge Bundy (presidente de la Fundación Ford), Howard R. Dressner (secretario y consejero general), William P. Gormbley (de la división de Administración), Francis X. Sutton (vicepresidente adjunto) y Arthur D. Trottenberg (vicepresidente). 11 de octubre de 1973. Rockefeller Archive Center (Nueva York). Ford Foundation records. Latin American and the Caribbean Program on the 1973 Coup D'Etat in Chile. Series 1. Box 1. Folder 3, Oct. 1 - Oct. 9, 1973.

${ }^{60}$ Kalman Silvert era una voz autorizada dentro de la Fundación Ford para hablar y asesorar sobre las políticas institucionales a seguir sobre América Latina y, especialmente sobre Chile. De hecho, él había obtenido en 1947 la Penfield Fellowship para desarrollar en Chile una investigación sobre las industrias del país. En los años 50 ejerció como profesor visitante de la Universidad de Buenos Aires. Además de agente de la Fundación Ford en América Latina, fue un gran promotor de la enseñanza e investigación de los estudios latinoamericanos en Estados Unidos. De hecho, fue el primer presidente de la Latin American Studies Association. Vemos, por tanto, en el caso de la trayectoria de Silvert estos cruces entre filantropía, diplomacia
} 
Me gustaría avanzar el argumento de que, si no podemos distinguir fuertemente nuestras actividades del apoyo de la conducta política represiva en el país anfitrión, entonces deberíamos retirarnos. Pero, sin embargo, si vemos a nuestros programas en un país de acogida como una contribución al mantenimiento de un pluralismo que pueda llegar a florecer incluso en un futuro indefinido, o como una contribución al bienestar inmediato de las poblaciones tales como los niños desnutridos, entonces debemos permanecer incluso si algún beneficio marginal fluye hacia este gobierno anfitrión represivo. ${ }^{61}$

Esta postura intermedia que recomendaba Silvert de apoyar un "pensamiento esperanzador y de trabajo deseable" sería, efectivamente, la que seguiría la Fundación Ford respecto a Chile a la hora de financiar con becas y donaciones la creación de varios "centros académicos independientes", como el caso del ya citado CIEPLAN. ${ }^{62}$ La institución filantrópica estadounidense cerraría finalmente en 1975 la oficina de Santiago (la cual no abriría hasta 1991), trasladándose la sede regional a Lima y luego a Bogotá. 63 No obstante, retomaría con estos centros su política de ayudar al desarrollo de las ciencias sociales, al mantenimiento de equipos de investigación y a que los académicos y profesores pudieran conseguir, dentro de lo posible, algún grado de independencia. Pero lo haría esta vez, fuera del espacio estatal, pues el pensamiento social crítico en Chile se hizo mayoritariamente durante los años de la dictadura civil-militar desde el lado privado y desde los organismos internacionales.

académica e interrelaciones académicas norteamericanas y latinoamericanas. Fernando Quesada, "La marea del Pacífico. La Fundación Ford en Chile (1963-1973)", en Fernanda Beigel (dir.), Autonomía y dependencia académica. Universidad e investigación científica en un circuito periférico: Chile y Argentina (1950-1980), Buenos Aires, Editorial Biblos, 2010, 89-101; Richard N. Adams, "Some Personal Trivia about the Early Days", LASA Forum, Vol. XXXVII, No 2, 2006, 14-15.

${ }^{61}$ Memorándum interno de Kalman Silvert a David E. Bell. "Distatesful Regimes and Foundation Policies Overseas". 18 de octubre de 1973. Rockefeller Archive Center (Nueva York). Ford Foundation records. Latin American and the Caribbean Program on the 1973 Coup D’Etat in Chile. Series 1. Box 1. Folder 3, Oct. 1 Oct. 9, 1973.

62 José Joaquín Brunner y Alicia Barrios generalizaron el uso del concepto "Centros Académicos Independientes" (CAI) para referirse a la aparición a nivel regional de nuevos organismos y de difusión de las ciencias sociales bajo el contexto autoritario en el Cono Sur, especialmente. Trabajos posteriores, como el de Víctor Algañaraz, demuestran que en países como Argentina estos centros privados ya eran habituales en los años 50 del siglo XX. Víctor Algañaraz, Configuración histórico-estructural del Circuito Universitario Privado en Argentina (1955-1983): relaciones y tensiones entre la jerarquía eclesiástica, los gobiernos de facto y el sistema universitario, Tesis Doctoral, Mendoza, Universidad Nacional de Cuyo, 2014; José Joaquín Brunner y Alicia Barrios, Inquisición, mercado y filantropía. Ciencias sociales y autoritarismo en Argentina, Brasil, Chile y Uruguay, Santiago de Chile, FLACSO, 1987.

${ }^{63}$ Fundación Ford, 40 años en la región andina y Cono Sur, Santiago de Chile, Fundación Ford, $2003,95$. 


\title{
7. Conclusiones
}

Para las ciencias sociales chilenas, y también latinoamericanas por supuesto, el Golpe de Estado del 11 de septiembre de 1973 significó "un quiebre" del intenso desarrollo que venían experimentando desde mediados del siglo $\mathrm{XX}^{64}$. Como ya había indicado tiempo atrás Gino Germani "la inestabilidad política y la presencia de regímenes autoritarios impide o, en ciertos casos, anula el desarrollo de las ciencias sociales". ${ }^{65}$ Y concretamente eso fue lo que más o menos ocurrió. La dictadura civil-militar trastocó la cotidianeidad de todas aquellas instituciones, organismos y universidades dedicadas a la sociología y a las ciencias sociales. Además, y como hemos podido ver de forma precisa con los documentos escritos por los agentes de la Fundación Ford durante esos primeros días de incertidumbre e intranquilidad, hubo alumnos que fueron asesinados y docentes e investigadores padecieron la violación de los derechos humanos por parte del régimen represor. Otros marcharon del país, viéndose obligados a tomar el camino de exilio.

Esta inicial desarticulación violenta, hizo que las ciencias sociales salieran de las aulas universitarias para deambular después por los organismos internacionales, las ONG y los centros académicos independientes. Ese vacío dejado lo ocupó hegemónicamente la economía, una disciplina menos susceptible de ser sometida a la discusión política por la preeminencia del saber técnico y, por lo tanto, más servicial y acomodaticia al régimen. Sin embargo, los centros académicos independientes representarían, con el tiempo, una alternativa crítica y especializada, sobre todo en materias económicas. Ese nuevo tablero de juego mucho más tecnocrático y neoliberal que se abría en Chile y que posteriormente se extendería en América Latina con las posteriores dictaduras militares, ya lo había descifrado perfectamente Kalman Silvert en la carta que dirigió a David E. Bell -la cual vimos en el aparado anterior- y que definía con claridad el papel futuro que debería jugar la Fundación Ford:

\begin{abstract}
Ahora estamos en el punto en el que explicar detalladamente esta postura se hace necesario. Tenemos que decidir lo que significa para nosotros "jugar", y cómo hemos de pensar en los tecnócratas supuestamente apolíticos y si la confrontación entre la democracia y el autoritarismo realmente ha sido desteñida por un cambio en la naturaleza de la guerra fría y el aparente intercambio de problemas entre los países desarrollados y en desarrollo. ${ }^{66}$
\end{abstract}

\footnotetext{
${ }^{64}$ Paola Bayle, "Emergencia académica en el Cono Sur: el programa de reubicación de cientistas sociales (1973-1975)", Íconos, FLACSO-Ecuador, N 30, Quito, 2008, 51-63.

${ }^{65}$ Gino Germani, La sociología en América Latina: problemas y perspectivas, Buenos Aires, Editorial Universitaria, 1964.

${ }^{66}$ Memorándum interno de Kalman Silvert a David E. Bell. "Distatesful Regimes and Foundation Policies Overseas". 18 de octubre de 1973. Rockefeller Archive Center (Nueva York). Ford Foundation records. Latin American and the Caribbean Program on the 1973 Coup D’Etat in Chile. Series 1. Box 1. Folder 3, Oct. 1 Oct. 9, 1973.
} 
Esa necesidad por parte de la Fundación Ford de tomar decisiones sobre los programas futuros en Chile explicaría el apoyo financiero para la creación de CIEPLAN. Una iniciativa que inicialmente respondió a propósitos académicos e intelectuales por resguardar las ciencias sociales en un contexto de autoritarismo, como bien escribió Jeffrey Puryear, el agente de la institución filantrópica norteamericana que gestionó la beca para fundar ese centro académico: "Los miembros del personal de CEPLAN hicieron planes para desarrollar una base alternativa institucional para proteger su estabilidad a largo plazo y para mantener su programa de investigación crítica e independiente". ${ }^{67}$ Pero también este centro académico resultó ser una iniciativa de claro contrapeso crítico a la dictadura civilmilitar y, como así demostró la historia, estas donaciones sostuvieron un compromiso político que traspasó el ámbito académico y terminaron por penetrar, al final, en el terreno de la vida pública. ${ }^{68}$

Más allá de eso, y por todo lo visto anteriormente, se ha podido observar de forma abreviada cómo vivieron y sintieron los diplomáticos académicos de la Fundación Ford los sucesos del 11 de septiembre. Más en concreto, sus documentos y opiniones sirvieron como espejos para saber y entender el estado de las ciencias sociales antes de ese suceso histórico y sus repercusiones más inmediatas. De esta forma, los documentos reflejaron el gran período de producción local de conocimiento social, con una gran movilidad internacional, con una fuerte presencia de redes intelectuales y con un alto grado de autonomía, desarrollo e institucionalización. Toda esa fisonomía cambió con el Golpe de Estado.

Así pudimos rastrear en esos documentos algunos hechos que narran una desarticulación violenta de las ciencias sociales y que dan cuenta, también, del proceso de formación de los cuerpos burocráticos de la dictadura civil-militar y de la eclosión de los economistas de la Universidad Católica. Fueron testimonios que nos hablaban, en fin, de una ruptura radical de las ciencias sociales en el país y de la imposición autoritaria de las teorías neoliberales ortodoxas que repercutieron en este campo y que, a la larga, producirían costes políticos y consecuencias humanas y sociales dramáticas. Un corsé impuesto entonces que explica muchas de las situaciones económicas, culturales, sociales y políticas de hoy día, las cuales benefician a aquellos que siguen manteniendo una visión tergiversada y manipulada de la historia. Esperamos, por tanto, haber contribuido con las anteriores páginas y sus pequeños detalles a ofrecer una comprensión más cabal de la historia reciente de Chile y de sus ciencias sociales.

\footnotetext{
${ }^{67}$ Rockefeller Archive Center (Nueva York). Ford Foundation records. Grant number 76-00290. Grantee name "Corporation for Latin American Economic Research". Grant purpose "Support for research in Economic and Social Policy Issues". Request No. ID- 2976, 24 de julio de 1978, p. 4. El grupo original de CIEPLAN estuvo compuesto por José Pablo Arellano, René Cortázar Sanz, Ricardo Ffrench-Davis, Patricio Meller y Alejandro Foxley fungiendo como su presidente.

${ }^{68}$ Las donaciones de la Fundación Ford fueron claves, como así creemos, en la articulación de la oposición civil y democrática en Chile bajo los años de la dictadura civil-militar, pues además de financiar a CIEPLAN, también la institución filantrópica estadounidense ayudó a consolidar el movimiento de los derechos humanos en el país con becas y donaciones a la Vicaría de la Solidaridad. Fundación Ford, 40 años en la región andina y Cono Sur, Santiago de Chile, Fundación Ford, 2003, 38.
} 


\section{Referencias bibliográficas.}

Adams, Richard N. (2006) "Some Personal Trivia about the Early Days". LASA Forum, Vol. XXXVII, No 2, pp. 14-15.

Algañaraz, Victor (2013) "Between scientific autonomy and academic dependency: Private Research Institutes under dictatorship in Argentina (1976-1983). The case of FLACSO". En Beigel, Fernanda (ed.), The Politics of Academic Autonomy in Latin América (pp. 249-263). Londres: Ashgate.

Algañaraz, Víctor (2014) Configuración histórico-estructural del Circuito Universitario Privado en Argentina (1955-1983): relaciones y tensiones entre la jerarquía eclesiástica, los gobiernos de facto y el sistema universitario. Tesis Doctoral. Mendoza: Universidad Nacional de Cuyo.

Arnove, Robert; Pinede, Nadine (2007) "Revisiting the "Big Three" Foundations". Critical Sociology, $\mathrm{N}^{\mathrm{o}} 33$, pp. 389-425.

Beigel, Fernanda (2009) "La FLACSO chilena y la regionalización de las ciencias sociales en América Latina (1957-1973)". Revista Mexicana de Sociología, № 2, pp. 319-349.

Bayle, Paola (2008) "Emergencia académica en el Cono Sur: el programa de reubicación de cientistas sociales (1973-1975”. Íconos, FLACSO-Ecuador, Nº 30, pp. 51-63.

Bayle, Paola (2010) "La migración forzosa de una población calificada. El programa de Reubicación de Cientistas Sociales CLACSO y el exilio chileno (1973-1976)". En Beigel, Fernanda (dir.): Autonomía y dependencia académica. Universidad e investigación científica en un circuito periférico: Chile y Argentina (1950-1980) (pp. 233-269). Buenos Aires: Editorial Biblos.

Beigel, Fernanda (2010) "La institucionalización de las ciencias sociales en América Latina: entre la autonomía y la dependencia académica”. En Beigel, Fernanda (dir.): Autonomía y dependencia académica. Universidad e investigación científica en un circuito periférico: Chile y Argentina (1950-1980) (pp. 47-64). Buenos Aires: Editorial Biblos.

Braslavsky, Silvia E. (2017) "The Ford Foundation and the Relocation of Argentinian Scholars, 1966-1968”. Research Reports, Rockefeller Archive Center, Nueva York.

Brunner, José Joaquín (1985) "La participación de los centros académicos privados en el desarrollo de las ciencias sociales". Documentos de Trabajo, № 257. Santiago de Chile: FLACSO.

Brunner, José Joaquín (1988) El caso de la Sociología en Chile. Formación de una disciplina. Santiago de Chile: FLACSO.

Brunner, José Joaquín; Barrios, Alicia (1987). Inquisición, mercado y filantropía. Ciencias sociales y autoritarismo en Argentina, Brasil, Chile y Uruguay. Santiago de Chile: FLACSO. 
Calandra, Benedetta (2011) "La Ford Foundation y la Guerra Fría Cultural”. Americanía, No 1, pp. $8-25$.

Calandra, Benedetta (2012) "Del "terremoto" cubano al golpe chileno: políticas culturales de la Fundación Ford en América Latina (1959-1973)", en Benedetta Calandra y Marina Franco (eds.), La guerra fría cultural en América Latina. Desafíos y límites para una nueva mirada de las relaciones interamericanas. Buenos Aires: Editorial Biblos, pp. 133-149.

Calandra, Benedetta (2015) "De la selva brasileña a la capital de las ciencias sociales: proyectos modernizadores de la Fundación Ford en América, Latina, 1927-1965". Historia y Política, No 34, pp. 53-80.

Cárdenas, Juan Cristóbal (2015) "Una historia sepultada: el Centro de Estudios Socioeconómicos de la Universidad de Chile, 1965-1973 (a 50 años de su fundación)”. De Raíz Diversa, Vol. 2, № 3, pp. 121-140.

Cortés, Alexis (2012) "Modernización, dependencia y marginalidad: itinerario conceptual de la sociología latinoamericana". Sociologias, V. 14, 2012, pp. 214-238.

Faletto, Enzo (1999) "De la teoría de la dependencia al proyecto neoliberal: el caso chileno". Revista de Sociología, No 13, Departamento de Sociología, Facultad de Ciencias Sociales de la Universidad de Chile, pp. 127-140.

Franco, Rolando (2007) La FLACSO clásica (1957-1973). Vicisitudes de las Ciencias Sociales latinoamericanas. Santiago de Chile: FLACSO, Catalonoia.

Franco, Rolando (2013) La invención del ILPES. Santiago de Chile: Naciones Unidas, CEPAL.

Ffrench Davis, Ricardo (2003) Entre el neoliberalismo y el crecimiento con equidad. Santiago de Chile: LOM.

Fundación Ford (1973) Ford Foundation Annual Report. Nueva York: Fundación Ford.

Fundación Ford (2003) 40 años en la región andina y Cono Sur. Santiago de Chile: Fundación Ford.

Gárate, Manuel (2012) La revolución capitalista en Chile (1973-2003). Santiago de Chile: Ediciones Universidad Alberto Hurtado.

Garretón, Manuel Antonio (2014) Las ciencias sociales en la trama de Chile y América Latina. Santiago de Chile: LOM.

Germani Gino (1964) La sociología en América Latina: problemas y perspectivas. Buenos Aires: Editorial Universitaria.

Godoy, Hernán (1960) Orientación y organización de los estudios sociológicos en Chile. Santiago de Chile: Ediciones Universidad de Chile. 
Godoy, Hernán (1977) "El desarrollo de la sociología en Chile. Resumen crítico e interpretativo de su desenvolvimiento entre 1950 y 1973". Estudios Sociales, № 12, pp. 33-56.

Huneeus, Carlos (2016) El régimen de Pinochet. Santiago de Chile: Taurus.

Iglesias, Mónica (2016) "Saber y poder en la transición chilena: los pobladores como campo de disputa política", Revista de Historia, Vol. 2, N²3, pp. 65-94.

Krebs, Ricardo (1994) Historia de la Pontificia Universidad Católica de Chile: 1888-1988. Santiago de Chile: Ediciones Universidad Católica de Chile.

Lladser, Maria Teresa (1986) Centros privados de investigación en ciencias sociales en Chile. Santiago de Chile: Academia de Humanismo Cristiano, FLACSO.

Malagón, Javier (1991) “Cómo recibió América al exilio español”. En Portela Yáñez, Charo (ed.): Cincuenta años de exilio español en Puerto Rico y el Caribe 1939-1989 (pp. 33-45). La Coruña: Edicios Do Castro.

Morales, Juan Jesús (2012) “José Medina Echavarría y la sociología en Chile. El intento de constituir una "tradición sociológica" en la Escuela Latinoamericana de Sociología". Revista Central de Sociología, Universidad Central, Santiago de Chile, № 7, pp. 79-115.

Morales, Juan Jesús (2017) “Científicos sociales latinoamericanos en Estados Unidos: cooperación académica, movilidad internacional y trayectorias interamericanas alrededor de la Fundación Ford". DADOS - Revista de Ciencias Sociais, Vol. 60, № 2, pp. 473-504.

Morales, Juan Jesús (2017) José Medina Echavarría. Vida y sociología. México D.F., El Colegio de México.

Morcillo, Álvaro (2016) "La dominación filantrópica. La Rockefeller Foundation y las ciencias sociales en español (1938-1973)", en Álvaro Morcillo y Eduardo Weisz (eds.), Max Weber en Iberoamérica. Nuevas interpretaciones, estudios empíricos y recepción. México D.F.: Fondo de Cultura Económica, CIDE, pp. 573-605.

Moyano, Cristina (2016) "ONG y conocimiento sociopolítico durante la Dictadura: la disputa por el tiempo histórico de la transición. El caso de los Talleres de Análisis de Coyuntura en ECO, 19871992”. Revista Izquierdas, № 27, pp. 1-31.

Navarro, Juan José; Quesada, Fernando (2010) “El proyecto Camelot (1964-1965). La dependencia académica, entre el escándalo y el mito". En Beigel, Fernanda (dir.): Autonomía y dependencia académica. Universidad e investigación científica en un circuito periférico: Chile y Argentina (1950-1980) (pp. 145-167). Buenos Aires: Editorial Biblos.

Pereyra, Diego (2006) "American organizations and the development of sociology and social research in Argentina. The case of the SSRC and the Rockefeller Foundation (1927-19669)". Research Reports, Rockefeller Archive Center, Nueva York.

Pressacco, Carlos Fabián; Salvat, Pablo (2017), “Norbert Lechner: política y utopía en América 
Latina", Polis, No 47.

Quesada, Fernando (2010) "La marea del Pacífico. La Fundación Ford en Chile (1963-1973)". En Beigel, Fernanda (dir.): Autonomía y dependencia académica. Universidad e investigación científica en un circuito periférico: Chile y Argentina (1950-1980) (pp. 89-101). Buenos Aires: Editorial Biblos.

Quesada, Fernando (2015) La Universidad desconocida. El convenio Universidad de ChileUniversidad de California y la Fundación Ford. Mendoza: Universidad Nacional de Cuyo.

Ramos, Claudio (2014) "Local and Global Communications in Chilean Social Science: Inequality and Relative Autonomy”. Current Sociology, Vol. 62, No5, pp. 704-722.

Ramos, Claudio (2012) El ensamblaje de ciencia social y sociedad. Conocimiento científico, gobierno de las conductas y producción de lo socia. Santiago de Chile: Ediciones Universidad Alberto Hurtado.

Ramos, Claudio; Canales, Andrea; Palestini, Stefano (2009) "El campo de las ciencias sociales en Chile: ¿Convergencia disciplinar en la construcción del objeto de estudio?’. Cinta de Moebio, $\mathrm{N}^{\mathrm{o}}$ 33, pp. 171-194.

Rosende, Francisco (ed.) (2007) La Escuela de Chicago. Una mirada histórica a 50 años del convenio Chicago/Universidad Católica. Ensayos en honor a Arnold C. Harberger. Santiago de Chile: Ediciones Universidad Católica de Chile.

Ruiz, Carlos (2015) De nuevo la sociedad. Santiago de Chile: LOM.

Solari, Aldo; Franco, Rolando; Jutkowitz, Joel (1976) Teoría, acción social y desarrollo en América Latina. México: ILPES, Siglo XXI.

Valdés, Juan Gabriel (1989) La Escuela de Chicago. Operación Chile. Buenos Aires: Editorial Zeta.

Valdivia, Verónica (2003) El golpe después del golpe. Leigh vs. Pinochet. Chile 1960-1980. Santiago de Chile: LOM.

Vergara, Pilar (1985) Auge y caída del neoliberalismo en Chile. Santiago de Chile: FLACSO. 